\title{
DESIGN EMOCIONAL
}




\section{SOBRE OS AUTORES}

\section{Cecília da Fonte | cecidafonte@gmail.com}

Lattes: http://buscatextual.cnpq.br/buscatextual/visualizacv.do?id=K4808619A8

Possui graduação em Design pela UFPE, especialização em Artes Visuais pela Rede EAD Senac, e no momento está cursando o programa de mestrado em Design pela UFPE. Tem experiência na área de Design Gráfico e Motion Design, atuando principalmente com os seguintes temas: linguagem gráfica, motion graphics e animação.

Gabriele Santos | gabriele.sant@gmail.com

Lattes: http://buscatextual.cnpq.br/buscatextual/visualizacv.do?id=K4450076Z7

Mestranda em Design pela UFPE, especialista em Design Mobile pelo C.E.S.A.R-EDU (2010) e bacharel em Design pela UFPE. Desde 2006 atua profissionalmente, com interesse nas áreas de Design de Interação e Design de Interfaces. Atualmente é designer de interação no CESAR.

Matheus Luck | mIl3@cin.ufpe.br

Lattes: http:/llattes.cnpq.br/7996287668282321

Mestrando em Design pela UFPE, bacharel em Ciência da Computação pela UFPE (2012) e coordenador local do capítulo Recife da IGDA (International Game Developers Association). 


\section{J U UR NEY

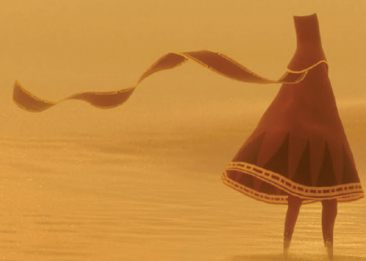

\section{O design visceral, comportamental e reflexivo}

de Journey: análise de um jogo digital com foco no design emocional

\section{The visceral, behavioural and reflexive design of Journey: Analysis of a video game with focus on emotional design}

Cecília da Fonte, Gabriele Santos, Matheus Luck

\section{Resumo}

Este artigo pretende analisar o jogo indie "Journey", lançado em 2012, utilizando como abordagem metodológica os "Três Niveis de Design" criados por Donald Norman, um dos autores mais importantes do Design Emocional. De acordo com Norman, este conceito é composto pelo design visceral, comportamental e reflexivo, que podem ser explorados no design de artefatos a fim de despertar emoções nos usuários. Dessa forma, em nossa análise, destacamos alguns dos elementos que compõem cada nível de design do jogo, observando como eles, juntos, funcionam de maneira eficaz com o intuito de proporcionar a experiência afetiva desejada por seus desenvolvedores.

\section{Abstract}

This article intends to analyze the indie game "Journey", released in 2012, using as methodological approach the "Three Levels of Design" created by Donald Norman, one of the most important authors of Emotional Design. This concept, as described by Norman, is composed by the visceral, behavioral and reflective design, which can be explored in artifacts to craft emotions on users. As so, in our analysis, we point out some of the elements that compose each level of design of the game, observing how they work together in an effective way to provide the affective experience desired by its developers. 
Jogos multijogadores são aqueles em que vários jogadores participam simultaneamente de uma mesma partida. No caso de Journey ele pode ser jogado individualmente ou em dupla (na companhia de outro jogador anônimo). Nesse caso, se algum dos dois jogadores se desconectar, o jogo automaticamente buscará um novo parceiro para o jogador restante. $A$ transparência desse processo faz com que, em muitos casos, o jogador sequer note a troca de parceiros.

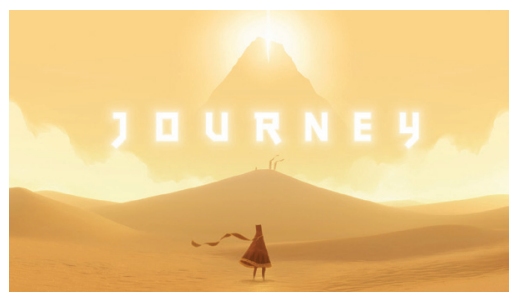

Journey visa proporcionar uma experiência emocional aos jogadores.

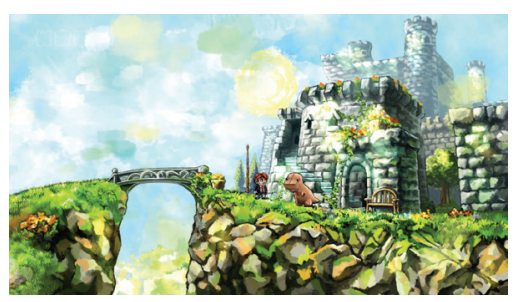

Cena de Braid. Jogo indie de plataforma que estimula a criação de um laço afetivo entre o protagonista e o jogador.

\section{INTRODUÇÃO}

O mercado de jogos digitais tem visto nos últimos anos a ascensão do setor independente, que tem desenvolvido games inovadores, fugindo dos padrões estabelecidos pela indústria das grandes companhias, dita mainstream. Geralmente criados por pequenos grupos de pessoas, com orçamentos reduzidos, e sem restrições contratuais (características que definem sua denominação como "independentes" - ou indies), esses jogos são envoltos por maior liberdade criativa, se comparados àqueles produzidos por empresas de grande porte, e frequentemente têm apresentado perfis experimentais, artísticos e emocionais.

Nesse contexto, destaca-se a empresa independente thatgamecompany que em 2012 lançou Journey, um jogo multijogador que busca criar uma conexão emocional entre os jogadores, valorizando atitudes colaborativas e afetivas entre eles. Através dessa produção, a equipe do estúdio norte-americano, possibilitou ao público uma experiência inovadora, pois ela diverge daquela estabelecida pela maioria dos jogos online, na qual frequentemente são estimuladas situações de confronto e/ou de hostilidade entre os indivíduos.

De acordo com a thatgamecompany, o método projetual de Journey partiu das emoções e da experiência que se desejava oferecer às pessoas. Na página oficial da empresa, a equipe também informa que uma de suas missões é enriquecer as experiências dos jogadores tornando-as significativas e inspiradoras. "Vem do coração. Nós passamos muito tempo pensando nas pessoas que vão jogar e na experiência que elas terão", diz Robin Hunicke, uma das integrantes do estúdio (HUNICKE, Robin. 2014).

Esse tipo de pensamento abordado por Hunicke, que tem o jogador como elemento central do projeto, focando nas suas emoções e experiências, tem se tornado cada vez mais comum no universo dos games independentes. Além de Journey, títulos como Limbo, Braid e Thomas Was Alone são produções que envolvem contextos emocionais, buscando oferecer novas vivências ao seu público-alvo.

Nesse sentido, podemos aproximar a abordagem afetiva desses games aos princípios do Design Emocional, que tem como um dos objetivos fornecer 
ferramentas e conhecimentos para a criação de artefatos ou serviços que sejam projetados a partir das emoções que se deseja evitar ou despertar nos indivíduos; ou seja, tendo o seu o design centrado no usuário.

Dentre os principais representantes dessa vertente do Design, temos Donald Norman que em seu livro "Design Emocional: Por que adoramos (ou detestamos) os objetos do dia-a-dia", explica que a emoção é resultado de três níveis de processamento cerebral humano: o nível visceral, o comportamental e o reflexivo. 0 autor argumenta que esses três níveis podem servir como embasamento para o desenvolvimento de artefatos de design, direcionando projetos a partir de três estratégias distintas: design para aparência (ou design visceral), design para facilidade de uso (design comportamental) ou design para significados e reflexão (design reflexivo) (TONNETO e DA COSTA, 2011, p. 135).

É nesse contexto que a presente pesquisa se insere. Visto que o universo de jogos independentes tem se aproximado das abordagens aplicadas pelo Design Emocional, acreditamos que relacionar esses dois campos pode ser uma maneira de fornecer contribuições para uma melhor compreensão do universo indie dos jogos, que ainda é pouco explorado em trabalhos acadêmicos, assim como fornecer um caminho que poderá guiar as abordagens metodológicas dos game designers que projetam para as emoções e experiências.

Desta forma, este artigo tem a finalidade de realizar um estudo de caso tendo como objeto central o jogo Journey, mencionado anteriormente, utilizando como embasamento os três níveis de processamento de Donald Norman. Para tal, iniciaremos uma análise do jogo, destacando alguns dos elementos que compõem o seu design visceral, comportamental e reflexivo. Ao adaptar esse conceito de Norman ao projeto de Journey, tem-se a intenção de compreender como a equipe explorou cada elemento do jogo (visual, trilha sonora, narrativa, etc) a fim de proporcionar a experiência emocional desejada.

A composição deste documento envolve, além da introdução, três seções: A primeira tratará dos três níveis de processamento emocional descritos por Donald Norman, trazendo as explicações teóricas sobre essa abordagem metodológica que servirá como base para a seção seguinte. $\mathrm{Na}$ 


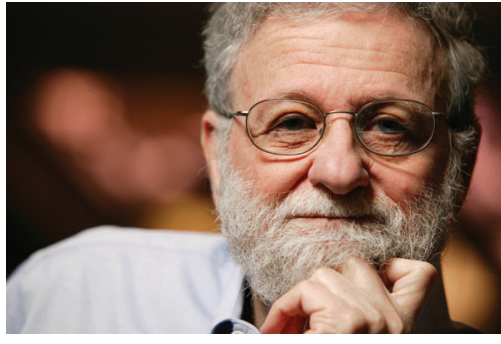

Donald Norman: um dos pesquisadores mais referenciados do Design Emocional.

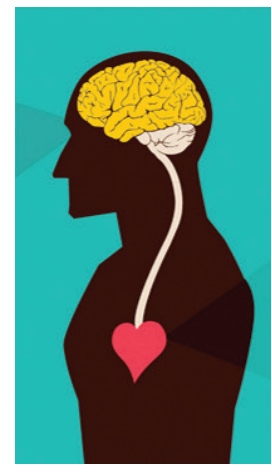

Design Emocional: Foco nas emoções dos usuários. segunda seção será observada a relação de Journey com esses três níveis de processamento, destacando-se alguns dos elementos e características que compõem o design visceral, comportamental e reflexivo do jogo. Por fim, teremos as conclusões e os possiveis desdobramentos deste trabalho.

\section{DONALD NORMAN E OS TRÊS NÍVEIS DE PROCESSAMENTO: VISCERAL, COMPORTAMENTAL E REFLEXIVO}

O campo do Design Emocional emergiu por volta da década de 1990, alinhando-se às abordagens metodológicas centradas no usuário. Seu objetivo é facilmente confundido, como se o designer pudesse projetar emoções: alegria, satisfação, entre outras. Na verdade, segundo Tonetto e Da Costa (2011), o objetivo desta vertente do Design é trazer um olhar detalhado para as experiências de caráter subjetivo, inerentes aos seres humanos, apoiando-se principalmente na psicologia, com a intenção de fornecer ferramentas e conhecimentos para projetos que têm o intuito de evitar ou despertar determinadas emoções.

O Design Emocional também está ligado ao Design de Experiência. Nesse sentido, Tonetto e Da Costa (2011) descrevem que a experiência emocional é apenas uma das dimensões da experiência. Baseando-se em Hekkert (2006), os mesmos autores apresentam a definição de que toda product experience é o conteúdo afetivo que surge da interação entre o usuário e o produto, incluindo o grau em que os sentidos são gratificados: experiência estética, experiência de significado e experiência emocional.

Essa interação entre os seres humanos e o design de produtos, ou serviços, sob o ponto de vista das emoções, é um dos principais focos das pesquisas desenvolvidas no campo do Design Emocional, que tem como autores representativos os pesquisadores Patrick Jordan, Pieter Desmet e Donald Norman - este último sendo um dos mais referenciados da área pois, em seu livro "Design Emocional: Por que adoramos (ou detestamos) os objetos do dia-a-dia" (2008)", apresenta conceitos e conhecimentos de forma clara e objetiva, contribuindo para a difusão do Design Emocional.

Nessa publicação o autor apresenta os "Três níveis de processamento emocional", explicando que a emoção é resultado de três níveis da 
estrutura cerebral humana: o visceral, o comportamental e o reflexivo. Este conceito, criado por Norman e outros professores do Departamento de Psicologia da Northwestern University, serve como embasamento para a análise e desenvolvimento de artefatos de design.

Para uma melhor compreensão do assunto, a seguir será feita uma descrição mais detalhada sobre cada um dos níveis, relacionando-os com o campo do design.

O nível visceral é a camada automática, pré-programada. Representa o mecanismo que analisa o mundo real e dá respostas biológicas. Trata dos aspectos físicos e sensoriais que repercutem a partir de um primeiro impacto com um produto, afetando o sistema motor e sensorial humano. O prazer de caráter visceral está voltado às relações automáticas de adoração, desejo, atração, ocasionadas normalmente por sons, cores, formas, e outras características sensoriais e estéticas que podem envolver um artefato.

Segundo Norman (2008), algumas condições parecem produzir respostas semelhantes (positivas ou negativas) de forma automática nas pessoas, podendo ser entendidas como padrões no que diz respeito ao nível visceral. Entre as condições que produzem respostas negativas estão: altitudes excessivas; sons altos, duros ou abruptos; luzes súbitas; calor ou frio excessivos; multidões, dentre outros. Entre os aspectos viscerais que ativam o estado afetivo positivo estão: lugares aquecidos e bem iluminados; sabores e odores doces; cores "alegres", de matizes intensas e saturadas; sons "tranquilizadores", melodias e ritmos simples e harmoniosos; formas simétricas; sensações, sons e formas "sensuais".

É importante lembrar que essas respostas não representam de fato uma unanimidade, afinal se uma pessoa lida diariamente com alturas excessivas poderá não ter mais respostas negativas diante desse estímulo, uma vez que já se adaptou a essa condição.

Destaca-se que é no nível visceral onde encontramos uma maneira para explicar a atração ou repulsão automática que temos ao perceber algum produto. Muitos de nós já nos deparamos com uma situação em que olhamos um produto e antes de saber como ele funciona ou quanto custa, pensamos "Uau, que lindo!" - um exemplo típico do nível visceral agindo sobre nós.

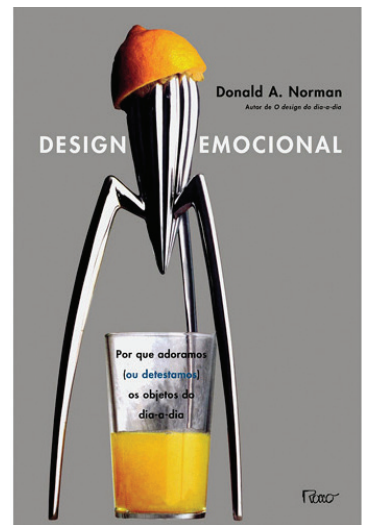

Capa do livro de Donald Norman Design Emocional: Por que adoramos (ou detestamos) os objetos do dia-a-dia.

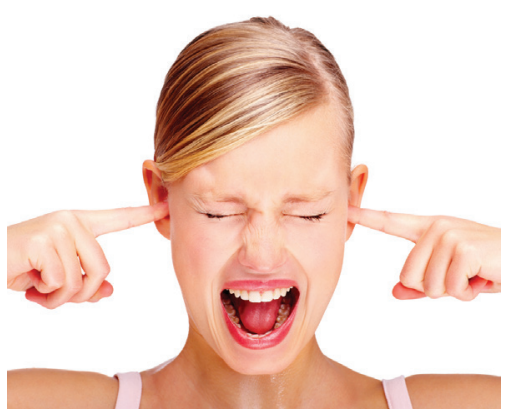

Sons altos agem no nivel visceral, podendo causar respostas automáticas negativas nas pessoas. 


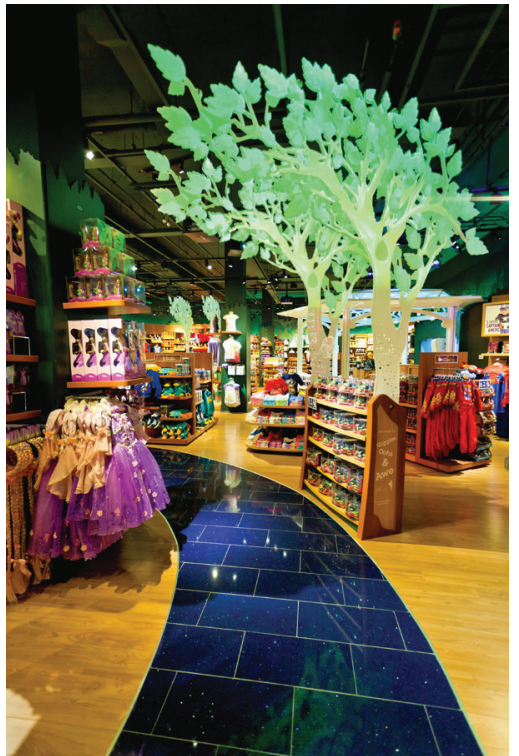

As lojas da Disney buscam atrair os consumidores, estimulando o nível visceral dos mesmos através das suas belas e lúdicas decorações e arquitetura.

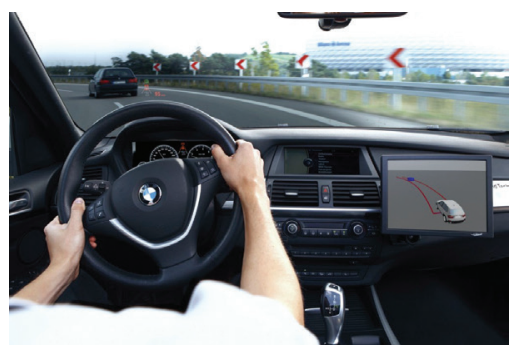

A facilidade de dirigir um carro está diretamente relacionada ao nível comportamental.
O nivel comportamental contém os processos cerebrais que controlam o comportamento cotidiano. Representa o uso e desempenho objetivo das funções de um produto: como o usuário compreende e opera o produto e consequentemente como o mesmo se comporta. Este nível também pode gerar respostas positivas ou negativas. Usuários frustrados ou confusos, por exemplo, atingirão um estado negativo. 0 nivel comportamental é também despertado em operações rotineiras que são executadas de forma subconsciente depois de um tempo de prática. 0 prazer comportamental está ligado à sensação de controle, de dominar a situação. A pessoa é capaz de sentir a satisfação ao fazer bem determinada coisa.

Por exemplo, logo que alguém aprende a dirigir é comum se atrapalhar no momento de trocar as marchas ou confundir-se na forma correta de pisar nos pedais; mas com o tempo, o motorista ganha mais confiança e já possui experiência para fazer muitos desses comandos de forma automática. Um bom design comportamental permite que o novo motorista rapidamente sinta-se à vontade ao dirigir, tendo o controle da situação, de maneira facilitada e prazerosa.

Muitas facilidades são inseridas nos produtos com o objetivo de poder otimizar as atividades desempenhadas pelos usuários. Embora possa parecer óbvio fazer um produto funcionar bem, as necessidades das pessoas não são tão evidentes assim. Desde quando as pessoas começaram a ter a necessidade de colocar um copo de café no carro enquanto dirigem para o trabalho? A pesquisa, por meio de observação do uso, permitiu que os pesquisadores identificassem essa oportunidade. Inovação é um gargalo do design comportamental, e essa facilidade possibilitada pelo espaço para copo de café nos carros representou uma inovação que foca em facilitar o uso do produto.

O nível reflexivo envolve a parte contemplativa do cérebro, o pensamento mais elevado dos humanos. Representa o uso sob o ponto de vista subjetivo, os aspectos de ordem intangivel, abrangendo particularidades culturais e individuais, memória afetiva e significados atribuídos aos produtos e ao seu uso. 0 prazer que origina no nivel reflexivo exige estudo e interpretação. De todos os três níveis, esse é o que apresenta maior vulnerabilidade e oscilação, pois depende das variações de cultura, grau de instrução e experiências vivenciadas pelas pessoas. 
Relembrando os aspectos viscerais que normalmente geram respostas negativas, como a altura excessiva, surge uma reflexão: por que algumas pessoas, mesmo com medo, andam de montanha-russa, saltam de paraquedas ou praticam algum esporte radical? Segundo Norman (2008), pode haver duas respostas. A primeira delas pode ser a de que algumas pessoas adoram sentir medo: elas possuem as reações automáticas de medo e frio no estomago, provocado pelas subidas e descidas da montanha russa, mas gostam da descarga de adrenalina e da sensação de perigo. A segunda opção vem do nível reflexivo, envolvendo os sentimentos consequentes de andar de montanha-russa, o orgulho de dominar o medo e poder gabar-se disso depois. Nesse exemplo, dois níveis estão em disputa: 0 nível visceral e o reflexivo. Entretanto Norman argumenta que o nível visceral é o único que pode anular todos os outros níveis.

O fator "tempo" também é uma variável importante para distinguir os níveis. Os níveis visceral e comportamental se referem ao momento atual. São as experiências e respostas geradas quando se está vendo ou usando um produto "agora". O nível reflexivo, porém, se estende por muito mais tempo e pode envolver lembranças do passado ou considerações do futuro. Para Norman (2008), a interação entre cliente e produto ou serviço é importante nesse nivel, pois é nele que está o sentido de identidade própria do indivíduo e consequentemente a sua relação com a identidade do produto. Dessa forma sentido, essa relação pode refletir orgulho (ou vergonha) numa pessoa ao possuir determinado produto.

Conforme Norman, os três níveis de processamento estão associados entre si, e cada um deles tem o seu papel no "funcionamento integral de uma pessoa", sendo um superior ao seu anterior. Em relação ao campo do design, o profissional que projeta para despertar emoções pode direcionar o seu projeto para um dos três niveis considerando seus aspectos relevantes. Desse modo, diferentes estratégias seriam trabalhadas e o mapeamento dos produtos seria realizado de acordo com as características dos mesmos, da seguinte maneira:

- Design Visceral = Design para a aparência;

-Design Comportamental = Design para a facilidade de uso;

-Design Reflexivo = Design para reflexão, autoimagem, satisfação e lembranças;

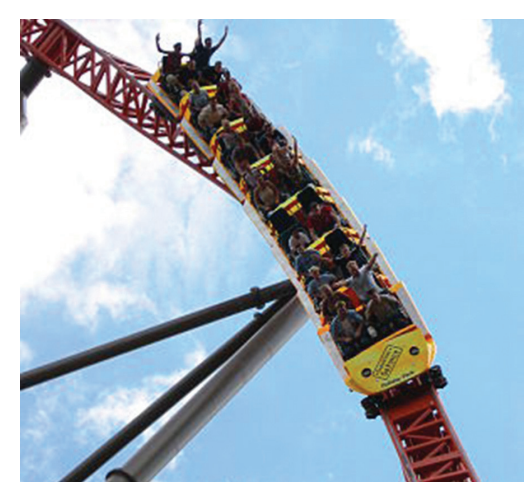

Na montanha russa as pessoas pagam para sentir medo. Nivel visceral (medo) versus reflexivo (orgulho de realizar a proeza).

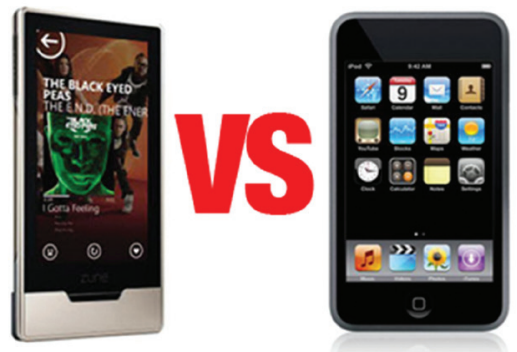

O Microsoft Zune Media Player foi lançado, em 2006, para competir com o iPod, mas não conseguiu obter sucesso. Através de uma aparência atraente e sendo fácil de usar, o Zune satisfazia nos niveis visceral e comportamental. Entretanto, era o iPod que monopolizava a experiência reflexiva dos usuários. Com um design bonito e funcional e um marketing inteligente, ele se transformou num icone cultural que representava um estilo pessoal e de identidade para os seus usuários. As pessoas tinham orgulho de possuir um iPod e vergonha de serem donas de um Zune. (LOMBARDI, 2013)

O iPod é um bom exemplo de um projeto que explora de maneira satisfatória os três niveis de processamento, garantindo sucesso frente aos seus concorrentes. 


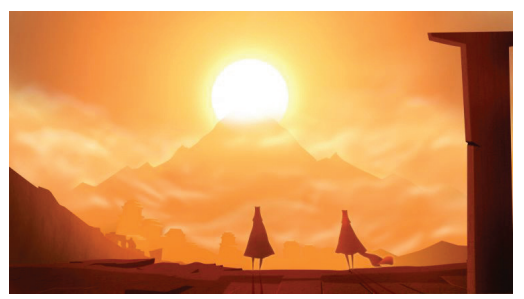

Cena de Journey. A conexão emocional que o jogo busca despertar em seus jogadores possibilita experiências enriquecedoras aos mesmos, que se jogassem individualmente não conseguiriam vivenciá-las. Em inúmeros depoimentos de pessoas que jogaram Journey o sentimento de companheirismo é mencionado como sendo quase inevitável.
Concluindo esta seção, é importante destacar que Norman explica que o design de um produto pode estar mais voltado a um desses níveis, porém os produtos de excelência são aqueles que atendem a todos os níveis de processamento de forma completa. E, conforme já mencionado, atingir o nivel reflexivo é garantir a identificação do usuário com o produto em um nivel emocional mais elevado.

\section{JOURNEY E OS TRÊS NÍVEIS DE PROCESSAMENTO EMOCIONAL}

Antes de iniciar a análise de Journey, observando os elementos que compõem o seu design visceral, comportamental e reflexivo, será feita uma breve descrição do contexto que envolve o jogo, suas características, as experiências despertadas por ele e o objetivo da equipe de desenvolvedores ao criá-lo.

Journey é um jogo digital online para console (neste caso, o Sony Playstation 3), desenvolvido pela empresa independente thagamecompany. 0 jogo se passa num cenário desértico, por meio do qual o jogador vivencia a sua jornada sozinho ou em dupla (na companhia de outro jogador anônimo). 0 objetivo dos personagens é chegar ao topo de uma montanha, e para chegar até ela, eles devem passar por enormes dunas de areia, ventos uivantes, e antigas ruínas, explorando os mistérios de uma civilização passada.

Lançado em 2012, Journey ganhou inúmeros prêmios e é por muitos considerado uma obra de arte. 0 jogo tem cenários e animações de encantar os olhos, além de uma trilha sonora aclamada pela crítica, tendo sido a primeira trilha de um videogame a ser indicada ao Grammy de "Melhor Trilha Sonora".

Entretanto, talvez o principal componente explorado em Journey seja a experiência emocional que se pretende despertar nos jogadores. Em palestra na GDC (Game Developers Conference) de 2013, Jenova Chen, game designer e um dos criadores de Journey, explica que 0 processo criativo do jogo partiu da experiência e das emoções que a equipe desejava promover. 
Chen (2013) explica que, através do jogo, a empresa buscou fazer um redesign das experiências estabelecidas pela maioria dos jogos online que, segundo ele, frequentemente estimulam situações de confronto, hostilidade e de competição entre jogadores. Ou seja, fugindo dos padrões dos jogos online, a thatgamecompany objetivou criar uma conexão afetiva entre as pessoas, estimulando constantemente no jogo atitudes colaborativas entre elas. $O$ game designer acrescenta que sentimentos ligados ao mistério, ao desconhecido e ao espiritual, foram igualmente definidos inicialmente no projeto, contribuindo com a determinação da experiência emocional, como um todo, que se prendia criar para o jogador.

Relacionando a abordagem da empresa thatgamecompany ao produzir Journey e os três niveis de processamento de Donald Norman - em que temos o design visceral como aquele ligado à aparência, o comportamental ao desempenho de um determinado produto, e o reflexivo que diz respeito aos significados dos artefatos, acreditamos que é no nivel reflexivo que se concentra o processo de criação do jogo, pois as experiências emocionais e os sentimentos predominantes ao jogo - como os da afetividade e da espiritualidade, por exemplo - encontram-se na essência do design reflexivo, que se relaciona com o lado introspectivo do jogador, através de suas experiências, memórias e interpretações pessoais.

Entretanto, percebe-se que o design reflexivo de Journey, apesar de tomar as rédeas do processo projetual, atua fundamentalmente em conjunto com o design visceral e comportamental. A relação entre os três níveis é fortemente percebida, pois a experiência emocional do jogo surge através de uma conexão efetiva entre o seu design visceral (representado principalmente pelos aspectos visuais e a trilha sonora), comportamental (presente nas ações e funcionamento do jogo) e reflexivo (composto pelos significados da sua narrativa e do que emerge a partir dela).

A seguir iremos abordar alguns elementos do jogo que se relacionam com cada uma das três camadas de processamento a fim de esclarecer um pouco do processo projetual do game.

\section{Design Visceral}

Como vimos anteriormente, o nível visceral envolve as respostas biológicas que damos em um primeiro impacto com um determinado

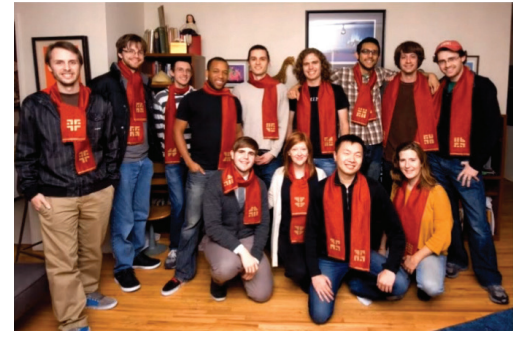

Equipe de desenvolvedores de Journey. 
Matt Nava, diretor de arte de Journey, explica que a escolha de um deserto para compor o cenário do jogo se deu a partir do desejo de unir os jogadores. Dessa forma, ele buscou criar um ambiente "solitário", sem distrações, que fizesse com que os jogadores quisessem estar perto um do outro. (NAVA, 2014)

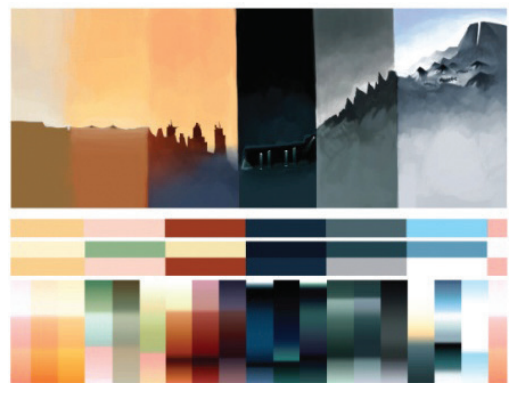

Uso de cores em Journey produto. Nessa camada, elementos físicos e sensoriais como cor, formas, sons e texturas são importantes no estímulo ao prazer de caráter visceral.

O design visceral de Journey, composto pelos seus aspectos visuais, sons e trilha sonora, cumpre um papel importantíssimo no jogo, especialmente porque o mesmo não possui diálogos, narração, ou texto. Ou seja, a transmissão da história do game e a comunicação entre os jogadores ocorrem através desses elementos que, juntos, ajudam a despertar as emoções e experiências desejadas, usando meios sensoriais.

Nesse sentido, o compositor da trilha sonora, Austin Wintory, explica que ele e o diretor de arte de Journey, Matt Nava, foram parceiros ao criar esses elementos. Austin explica que um dos seus objetivos ao produzir a trilha foi associá-la ao esquema de cores utilizadas em cada fase da jornada, a fim de estabelecer a atmosfera e as sensações pretendidas em cada uma dessas etapas (WINTORY, Austin).

Em uma entrevista para o site FastCoCreative, Jenova Chen explica que o esquema de cores do jogo inicia com tons em baixo contraste, iluminação nublada e variações de amarelo. Mais adiante, quando o jogador está perdido no subterrâneo, os designers optaram pelas cores frias e escuras, tons de azul, ciano e verde associando-as à sensação de submersão. Já, ao final da jornada, clímax do jogo, a intenção foi trazer cores para despertar o sentimento de liberdade e plenitude como o azul do céu.

Conectadas à paleta de cores, as músicas (todas instrumentais) se integram ao andamento do jogo de maneira natural e fluida. Para tal, Wintory também se uniu ao designer de som, Steve Johnson, para que a trilha e os efeitos sonoros do jogo trabalhassem juntos. Aclamada pela crítica e vencedora de inúmeros prêmios, a trilha sonora se baseia principalmente no violoncelo. "Um grande concerto de violoncelo onde você é o solista e todos os outros instrumentos representam o mundo ao seu redor", explica Wintory. As melodias criadas pelo compositor emocionam os jogadores, estimulando a sua percepção sensorial e despertando neles respostas biológicas e automáticas, como explica Mallory (2012): "Eu perdi a conta do número de vezes que as interpretações sutis e delicadas de Wintory me deixaram arrepiado". 
Nesse contexto, é interessante destacar o sucesso de dois elementos que compõem o design visceral de Journey frente ao público. 0 primeiro trata da direção de arte. Visto o número de fãs de Journey ao redor do mundo e o interesse de muitos em compreender como o processo criativo da arte conceitual se desenvolveu, Matt Nava (diretor de arte), decidiu compartilhar a sua criação com todos, publicando o livro "The art of Journey" que conta um pouco do processo projetual dos aspectos visuais do game. Já o segundo elemento diz respeito à sua trilha sonora, que foi lançada em um CD com 18 faixas, alcançando em sua primeira semana de lançamento mais de 4.000 cópias vendidas, a segunda melhor atuação de um álbum de trilha sonora de video game na história (CAULFIELD, 2012).

Concluindo esta breve análise sobre o design visceral de Journey, também é importante destacar rapidamente que o design das formas dos personagens e de alguns elementos do cenário também podem promover respostas biológicas, atraindo ou amedrontando os jogadores. As formas sinuosas das indumentárias dos protagonistas, por exemplo, são acolhedoras, despertando leveza e suavidade aos mesmos. Já as formas mais geométricas e retilineas das ruínas e seres agressivos ajudam a criar uma atmosfera de suspense e mistério na jornada do jogador. As texturas também são elementos que podem despertar emoções viscerais. Os glifos brilhantes, símbolos que aparecem ao longo do jogo, atraem a atenção do jogador, que deve coletá-los para receber recompensas.

Compreendemos, através das observações aqui realizadas, que o design visceral de Journey cumpre de maneira satisfatória e essencial o seu papel na promoção de emoções, sensações e percepções sensoriais. Ao estar associado às ações e à narrativa do jogo, ele está constantemente ligado ao design comportamental e reflexivo do mesmo. Mais adiante poderemos entender melhor essa relação, quando será esclarecido o funcionamento do game e a história da jornada.

\section{Design Comportamental}

O design comportamental trata de como o usuário compreende e opera o produto e consequentemente como o produto se comporta. Nesse sentido, o desempenho do artefato deve ser eficiente e o seu uso
Como não existem diálogos ou informação textual no jogo, a comunicação dos jogadores se aproxima do nivel visceral, pois pode acontecer através da emissão simultânea de um som (uma nota musical) por cada um deles. (Mais detalhes sobre a comunicação dos jogadores serão vistos na barra lateral da próxima seção).

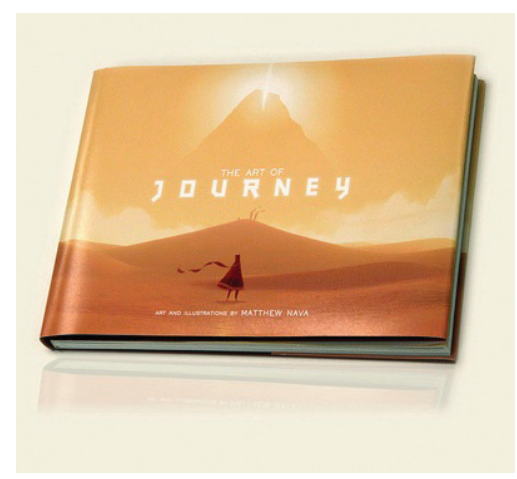

Livro "The art of Journey" escrito pelo diretor de arte do jogo, Matt Nava.

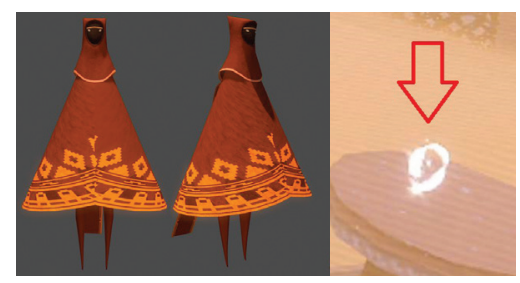

Forma das Indumentárias dos personagens de Journey e textura brilhante dos glifos, símbolos que devem ser coletados para o ganho de recompensas. 


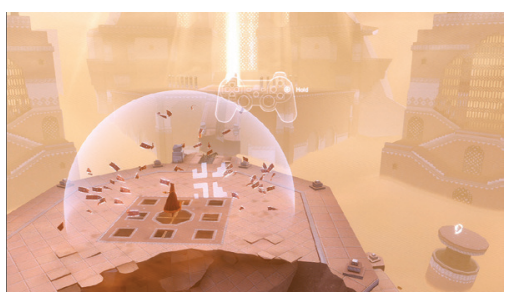

A imagem do controle surge para indicar quais os botões e comandos necessários para a realização de determinadas ações como mover, flutuar, entre outras.

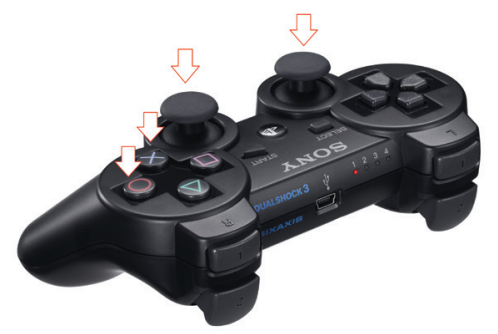

As quatro setas indicam as duas alavancas e os dois botões do controle que são utilizados para jogar Journey (alavanca esquerda, alavanca direita, botão X e botão O). prazeroso para que sejam despertadas emoções positivas nos usuários. Em Journey podemos indicar que os elementos que compõem o seu design comportamental dizem respeito a como o jogo funciona e como o jogador o compreende e interage com o mesmo e com outros jogadores. Sabendo que o funcionamento deste game envolve inúmeras ações e detalhes, nesta seção serão escolhidas apenas algumas situações que indicarão o desempenho comportamental do jogo.

A primeira delas trata da compreensibilidade do jogador em relação ao uso do controle do console. Nos momentos do game em que o jogador se depara com ações nunca antes realizadas, uma imagem do controle aparecerá na tela indicando quais os botões necessários para a realização de tais ações. Se o jogador acionar o botão errado, ele não irá progredir no jogo e ao voltar à mesma posição inicial, a orientação continuará surgindo na tela até que ele tenha aprendido a executar o comando. Também é importante mencionar que, de todos os 17 botões disponiveis no controle, Journey requer o uso de apenas duas alavancas e dois botões para ser jogado. Dessa forma, o jogador consegue "mergulhar" na experiência do jogo, sem ter de acionar constantemente uma série muito complexa de comandos.

Além de facilitar a operação do jogo, oferecendo orientações sobre a manipulação do controle, Journey também deixa claro ao jogador quais são os objetivos da jornada e como ele pode interagir com o game e com outros jogadores. Essa comunicação jogo-jogador se dá através do mundo que o cerca em conjunto com suas músicas, mecânicas e elementos gráficos pois, como vimos anteriormente, não existe comunicação verbal em Journey.

Exemplo disso acontece logo no início do jogo quando o jogador se depara com um vasto deserto, no qual se destaca uma montanha de cume brilhante, que deve ser escalada para que se atinja o objetivo principal da jornada. Nesse momento, é o cenário que irá estimular a intuição do jogador que sente que é para lá que deve seguir. Mas, caso ele não compreenda esse objetivo, ao longo de sua jornada ele será constantemente guiado pelo jogo, seja pela presença de bandeiras indicando a direção, ou até mesmo por rajadas de vento que irão o impedilo de prosseguir o caminho, caso siga o rumo contrário.

Nesse contexto, também vale ressaltar que se o jogador estiver jogando em dupla, junto a um companheiro mais experiente, este naturalmente irá 
orientá-lo, indicando quais caminhos deve seguir e até o ensinando a realizar tarefas. É importante destacar também que o jogo promove, constantemente, atitudes colaborativas entre eles a fim de estimular a criação do vínculo emocional desejado. Dois personagens ao se tocarem, por exemplo, recuperam a sua capacidade de voar, se a mesma tiver sido perdida.

Outro aspecto que deve ser mencionado diz respeito a um dos elementos que mais desperta o prazer comportamental nos jogadores: a locomoção dos personagens. "O simples ato de se movimentar é uma das partes mais agradáveis do jogo", diz Nick Harper (2012) ao explicar o que sente ao manipular o seu personagem no jogo. Os personagens podem andar, surfar nas dunas de areia, voar, coletar tecidos para voar distâncias ainda maiores, tudo isso realizado com operações simples e animações suaves e delicadas. Nesse contexto, Harper também explica que o design dos personagens, que têm pernas pontiagudas, ajuda a deixar a mecânica de locomoção ainda mais fluida.

Vimos anteriormente, que um bom design comportamental é aquele que permite que o usuário, em sua interação com o produto, tenha o controle da situação, de maneira facilitada e prazerosa. A partir dos comentários feitos nessa seção, pode-se sugerir que Journey tem um design comportamental excelente. Pois, fornecendo orientações aos jogadores, apresentando um simples funcionamento e promovendo formas criativas e facilitadas para a realização da interação entre personagens e sua locomoção, ele favorece a compreensão dos jogadores, despertando neles uma experiência rica em estados afetivos positivos (prazer, satisfação, etc).

Em conjunto com o design visceral, através dos cenários e sons, por exemplo, o design comportamental de Journey funciona de maneira fluida e intuitiva, associando-se a toda a atmosfera criada pelo jogo. 0 estímulo ao companheirismo e a interação dos jogadores, ao ser realizado muitas vezes de maneira implícita e natural, auxilia no despertar da experiência emocional desejada, favorecendo a criação de um vínculo afetivo entre eles que chega a atingir o design reflexivo, gerando significados e memórias pessoais.

\section{Design Reflexivo}

Segundo Norman, no nível reflexivo terão importância aspectos de ordem intangível, abrangendo particularidades culturais e individuais, memória

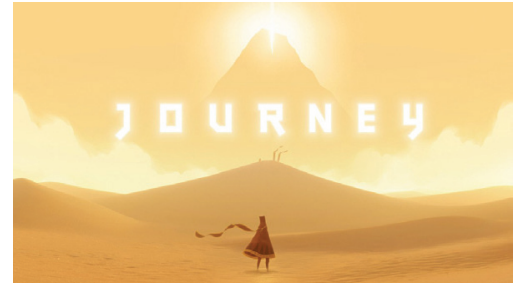

A montanha do jogo se destaca na paisagem, indicando ao jogador qual o destino que ele deve seguir.

A comunicação dos jogadores no jogo é auxiliada pelo design visceral, sendo realizada de maneira simples e fácil de ser praticada. Ela pode ocorrer de duas maneiras:

1. Quando em contato com areia e neve, por exemplo, os jogadores podem deixar rastros, e o movimento dos lenços usados por eles pode "desenhar" formas e símbolos no ar.

2. Através da emissão simultânea de um som (uma nota musical) e um símbolo; ambos diferentes para cada jogador. Quando fora do alcance visual, o símbolo é substituído por um brilho branco em alto contraste, apontando na direção do jogador que está emitindo seu som.

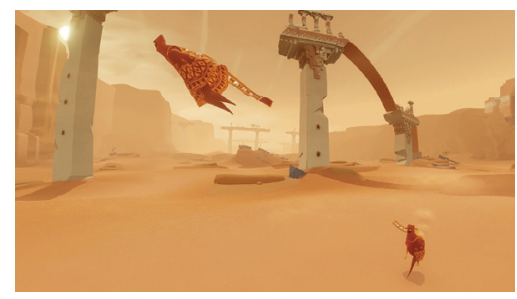

Personagem do jogo voando. 


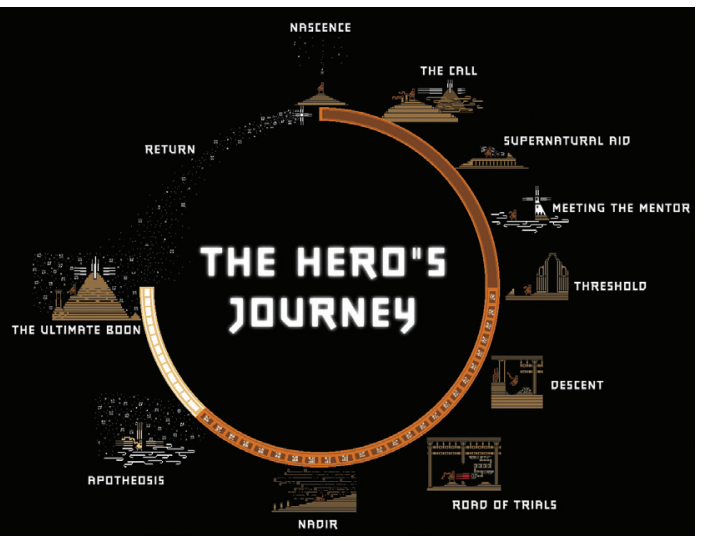

Estrutura do Monomito usada por Journey (JourneyStories.tumblr.com)

A análise completa feita pelo Extra Credits sobre como Journey utiliza o Monomito como recurso narrativo pode ser vista em:

http://youtu.be/SWKKRbw-e4U

(Pt. 1)

http://youtu.be/QVqT8s7bOTQ (Pt. 2)

\footnotetext{
"A Partida refere-se à saída do herói em direção à sua jornada, a Iniciação é composta pelas aventuras do herói ao longo de seu caminho; e o Retorno aborda o momento em que o herói retorna a sua casa, com os conhecimentos que obteve ao longo da jornada". (WIKIPEDIA).
}

afetiva e significados atribuídos aos produtos e ao seu uso. Nesta seção abordaremos o design reflexivo de Journey, apontando alguns elementos que se associam a questões subjetivas e simbólicas, como a narrativa do jogo e a relação de identidade que ele estabelece com seu público.

O nome do jogo já traz uma pista sobre sua história. Journey, palavra em inglês para "jornada", segue um modelo narrativo bastante difundido, intitulado de "A Jornada do Herói" ou "Monomito". Esse modelo foi inicialmente descrito em 1949 pelo escritor Joseph Campbell. Sua estrutura e os elementos que ela deve conter apresentam um caráter universal e atemporal. Ou seja, seguindo cada estágio proposto, a narrativa se torna mais propensa à aceitação de diferentes culturas, em diferentes momentos históricos.

Norman(2008) explica que o nivel reflexivo está mais suscetível às variações de cultura e tempo. Por exemplo, o que uma cultura acha interessante, a outra pode não achar. 0 mesmo acontece com o momento em que a ação acontece: podemos adorar um filme hoje, mas daqui a três anos não acharmos mais graça nele. A partir dessa observação podemos sugerir que a estrutura universal e atemporal do Monomito, seguida pelos desenvolvedores de Journey, possibilita um maior alcance do nível reflexivo de jogadores de diferentes perfis, fazendo com que eles vivenciem de forma mais pessoal a história do jogo.

Journey se utiliza de uma versão simplificada do modelo de Campbell que originalmente incluía 17 estágios, divididos em três categorias principais: Partida (ou separação), Iniciação e Retorno. Segundo a Extra Credits (2012), a narrativa de Journey resume-se em 9 estágios (1-Chamado à Aventura, 2-Recusa do Chamado, 3-Auxílio Sobrenatural, 4-Ruptura do Limiar, 5-A Barriga da Baleia, 6-O Caminho das Provações, 7-A Expiação Perante o Pai, 8-Apoteose, 9-0 Retorno), cada um possuindo intenções especificas. A seguir descreveremos apenas três deles, com o objetivo de revelar algumas ações de caráter subjetivo de Journey.

No Chamado à Aventura, primeiro estágio, há o destaque para a revelação da montanha, que indica o objetivo do jogo, despertando curiosidade no jogador e convidando-o a iniciar o desafio: chegar ao cume da montanha. 
O sexto estágio, O Caminho das Provações, representa o momento de escalada da montanha, quando o jogador precisa solucionar quebracabeças e buscar caminhos para se aproximar do cume. Nesse momento, os desafios constantes e o ambiente inóspito destacam a importância da proximidade e companheirismo dos jogadores. 0 último estágio, 0 Retorno, compõe o alcance do objetivo. Chegando ao cume da montanha, o jogador entra em um portal de luz, que o transforma em uma estrela e posteriormente o traz de volta à tela inicial, quando ele, mais experiente, pode começar uma nova jornada.

Journey explora a jornada dos jogadores rumo ao topo da montanha, confrontando-os com os mistérios de uma civilização passada e ao fim do jogo revela a história dos antepassados dos protagonistas: como eles surgiram, como prosperaram e ruíram. Entretanto, essa história possibilita interpretações ainda mais amplas e pessoais, gerando novos significados e estimulando reflexões acerca do ciclo da vida, da ressurreição, espiritualidade, entre outros. 0 envolvimento emocional que surge entre os personagens também desperta as memórias afetivas e pessoais de cada jogador, estimulando sentimentos ligados ao amor, união, cooperatividade e solidariedade.

Outro aspecto ligado às emoções do nível reflexivo refere-se à relação de identidade criada entre jogo e jogadores. Exemplo disso pode ser demonstrado através de inúmeras páginas disponibilizadas na internet reservadas às Fanarts, trabalhos de arte feitos por fãs de uma determinada obra. Nelas os jogadores expõem artefatos desenvolvidos por eles e que são carregados de memória afetiva, demonstrando o interesse dos mesmos em relacionar outros momentos de suas vidas com Journey, ou simplesmente exibirem sua admiração pelo jogo. Dessa forma, pode-se sugerir que Journey consegue atingir o patamar do nível reflexivo do design emocional, pois a relação jogo-jogador extrapola o uso do produto.

Como foi possível observar, o design reflexivo de Journey é carregado de significado. Através de sua estrutura narrativa, e das histórias que conta e desperta, o jogo gera reflexões sobre união, cooperação e afeto, ao mesmo tempo em que transpõe barreiras culturais e temporais, seguindo assim muitas das receitas do design emocional descritas por Norman. Uma aposta feita para conquistar não apenas consumidores, mas para gerar fãs do produto.

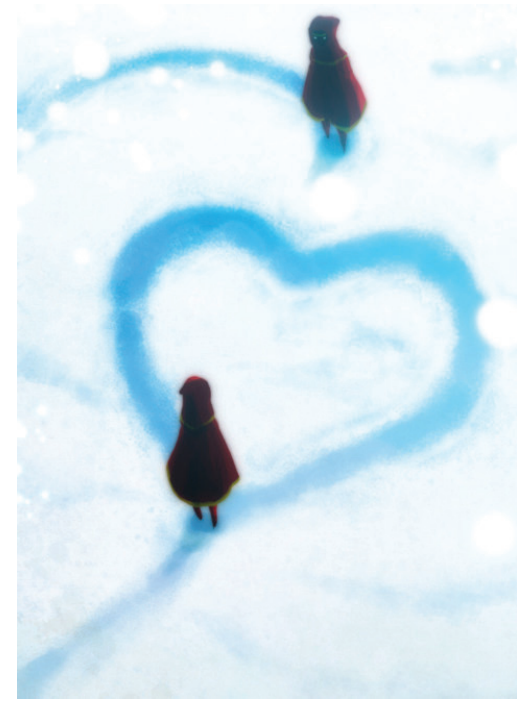

Desenho de um jogador no estágio "O Retorno". Nesse momento, muitos jogadores costumam fazer desenhos na neve para agradecer e cumprimentar o companheiro de jornada. O gesto foi reproduzido em um desenho, em nome da Sony, às vendas do jogo. 


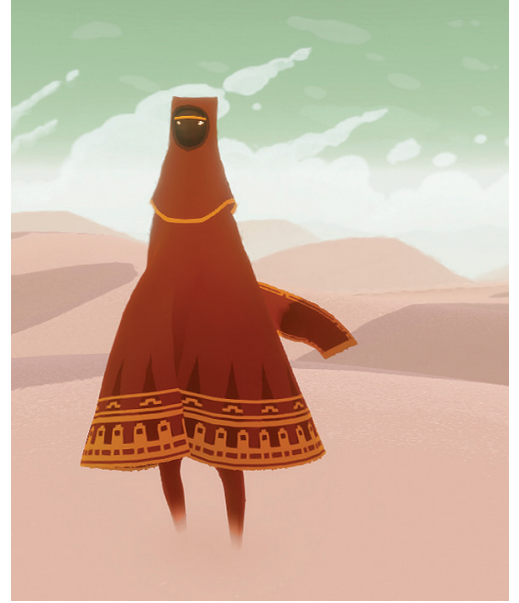

O design do personagem principal também facilita a universalização do jogo. Ele não representa nenhuma etnia, idade ou gênero específico, facilitando a aproximação de diferentes perfis de jogadores.

Austin Wintory, compositor da trilha sonora, também buscou remover influências culturais nas suas músicas com a finalidade de torná-las "tão universal e acultural quanto possivel". (WINTORY, 2014)

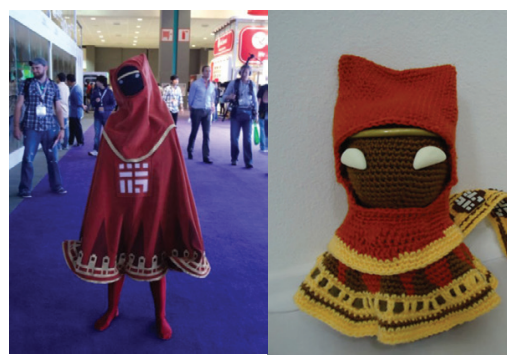

Fanart e Cosplays dos personagens do jogo - As pessoas criam objetos e se vestem do personagem, uma maneira de mostrar suas identidades e admiração pelo jogo.
É importante apontar que a experiência emocional como um todo, que os desenvolvedores de Journey buscaram promover, só acontece graças ao seu design visceral e comportamental, ou seja, a belíssima aparência do jogo e suas músicas, seu funcionamento prazeroso, e sua narrativa, juntas favorecem a criação de todos esses valores simbólicos que envolvem o game.

\section{CONSIDERAÇÕES FINAIS}

Este artigo teve o objetivo de realizar um estudo de caso de Journey, jogo lançado em 2012 para a plataforma PS3, que recebeu inúmeros prêmios e conquistou fãs no mundo inteiro. Desenvolvido pela empresa independente thatgamecompany, ele visa promover aos jogadores uma experiência emocional, carregada de significados.

Visto que a abordagem afetiva do jogo assemelha-se aos princípios do Design Emocional, que busca fundamentar projetos voltados às emoções dos indivíduos, decidiu-se por analisar o game sob o embasamento dos "Três níveis de Design", conceito criado por Donald Norman, um dos autores mais representativos da área. Este conceito é composto pelo design visceral (design para aparência), comportamental (design para facilidade de uso) e reflexivo (design que gera significados), e pode servir como direcionamento para a criação e análise de artefatos de design.

A análise dos três níveis de design do jogo buscou fornecer ferramentas para a compreensão do processo criativo do mesmo, pretendendo observar como a empresa explorou elementos visuais do game, sua trilha sonora, narrativa, entre outros, a fim de proporcionar uma experiência emocional aos jogadores.

Através das observações realizadas ao longo do estudo, podemos considerar que Journey é um produto que parte de uma estratégia mais voltada ao design reflexivo - que lida com a geração de significados, reflexões, autoimagem, memórias afetivas, simbolismos, entre outros. Mas, é sem dúvida, pelo fato do forte investimento nos demais níveis (design visceral e comportamental) que o jogo ganhou um grande 
reconhecimento no mercado, pois explora todos os níveis de maneira equilibrada e satisfatória, receita para produtos de sucesso.

Trabalhando em conjunto na promoção da experiência emocional desejada, os três niveis de design estão constantemente interligados, auxiliando um ao outro. 0 visceral que inclui cores, formas, texturas, sons e trilha sonora, consegue despertar emoções e percepções sensoriais, estabelecendo a atmosfera desejada em cada momento da jornada. 0 design comportamental, que envolve o funcionamento do jogo, também atua de maneira satisfatória, possibilitando experiências facilitadas e prazerosas. E o reflexivo desperta emoções de cunho contemplativo nos jogadores, promovendo interpretações pessoais e simbólicas e estimulando conexões afetivas e de identidade nos mesmos.

Deve-se relembrar, entretanto, que a análise aqui realizada buscou apontar uma visão geral dos elementos que compõem os três níveis de design do jogo, sem abrangê-los em sua totalidade. A estética e as mecânicas de Journey são ricas em detalhes e para abordar todas essas características e funções seria necessário produzir um estudo muito mais extenso.

Ao relacionar o universo dos games independentes ao campo do Design Emocional, esperamos poder contribuir para uma melhor compreensão dos jogos que são projetados para despertar emoções, assim como fornecer um caminho que poderá guiar as abordagens metodológicas de video games afetivos. Também esperamos ter oferecido novas perspectivas para a análise de artefatos de outros campos do design, pois os aspectos teóricos levantados por Norman podem servir como embasamento para qualquer projeto que tenha seu foco nas emoções do usuário.
Depoimentos de jogadores na internet:

"Journey é um jogo surpreendente.

Ele consegue criar uma experiência emocional muito forte, que muitos jogos com enredo extenso falham em atingir. Você vai se sentir na pele do viajante e talvez crie um vínculo emocional com outro jogador que você sequer conhece ou terá a chance de conversar. O visual é impressionante e a trilha sonora é excelente. Imersão absoluta!"

"Journey é um jogo fácil de jogar, completamente intuitivo e acessivel para qualquer pessoa."

"O que falar do jogo que te leva pra uma jornada simplesmente sem precedentes na história dos videogames com uma trilha sonora fantástica e uma jogabilidade que te deixa à vontade pra curtir a maravilha que o jogo é?"

"In a way that no other multiplayer game has done, I felt the necessity of companionship in Journey. In literally no MMO (Massively Multiplayer Online) I've ever played have I felt that need, but in Journey that sense of struggle feeds directly into a sense of camaraderie. It's deeply affecting".

"Journey é a metáfora universal da esperança do nosso próprio renascimento. Apenas uma vida, mas sempre em frente. $O$ que vale, como dizem, não é exatamente o final da caminhada, mas cada passo." 
"Em suma, Journey é uma grande metáfora. Metáfora do mundo que nos rodeia, da natureza da civilização e da vida em si. Uma jornada que começa a partir do momento que você nasce até os últimos instantes. E cada viajante é livre para sua própria interpretação e maneira de encarar este desafio".

"Acabei de terminá-lo e devo admitir que fazia muito tempo que eu não sentia uma sensação de tamanha paz e tranquilidade. Journey não é apenas um jogo, mas também um momento de pura contemplação e reflexão".

\section{REFERÊNCIAS}

CAULFIELD, Keith. 2012. Disponivel em: < http://www.billboard.com/biz/ articles/news/1097753/ chart-moves-newsies-cast-album-debuts-mtv-unplugged-returns-and-a-video

CHEN, Jenova. Designing Journey. Palestra concedida para a GDC (Game developers Conference).2013. Disponivel em: <http://www.gdcvault.com/play/1017700/ Designing>. Acesso em 10 jul. 2014.

CHEN, Jenova. Entrevista concedida para o FastCoCreate. 2012. Disponivel em http://www. fastcocreate.com /1680062/game-designer-jenova-chen-on-the-art-behind-his-Journey. Acesso em 7 jul. 2014.

JOURNEY STORIES. Disponivel em <http://Journeystories.tumblr.com/post/42992252591/herosjourney>. Acesso em 2.ago.2014

HEKKERT, P. Design aesthetics: Principles of pleasure in product design. Psyhology Science, 48(2): 157-172. 2006

HARPER, Nick. Journey and the art of emotional game design. 2012. Disponivel em <http://www. theguardian.com/technology/gamesblog/2012/nov/21/Journey-emotional-game-design>. Acesso em

HUNICKE, Robin. Depoimento disponivel em: <http:/www. polygon.com /2014/2/6/5385014/ingame-design-feelings-are-worth-more-than-brute-force>. Acesso em 9 jul. 2014.

INDIE GAMES. The Indie Game Movement. Disponivel em: < http://www.indiegames.com/what.htm> Acesso em 10 jul. 2014

LOMBARDI, Victor. Why we fail. Nova York: Rosenfield. 2013.

MALLORY, Jordan. Journey review: I want to go there. 2012. Disponivel em: <http://www.joystiq com/2012/03/01/Journey-review-i-want-to-go-to-there/>. Acesso em 18 jul. 2014.

NAVA, Matt. Depoimento do diretor de arte. Disponivel em: <http://designontherocks.blog.br/a-artede-Journey/>. Acesso em 18 jul. 2014

NORMAN, Donald. Design Emocional: Por que adoramos (ou detestamos) os objetos do dia-a-dia. Rio de Janeiro: Rocco. 2008.

THATGAMECOMPANY. Disponivel em <http://thatgamecom pany.com/>. Acesso em 15 jul.2014.

TONETTO, Leandro; DA COSTA, Filipe. Design Emocional: conceitos, abordagens e perspectivas de pesquisa. Rio de Janeiro: 2011.

WIKIPEDIA. Disponiveis em <http://en.wikipedia.org/wiki/Joseph_Campbell>;<http://en.wikipedia.org/ wiki/Monomyth>; <http://en.wikipedia.org/wiki/Phil_Cousineau>. Acesso em 02.ago.2014

WINTORY, Austin. Entrevista concedida pelo compositor. Disponivel em: <http://www.thesixthaxis. com/2012/03/15/interview-Journey-composer-austin-wintory/>. Acesso em 12 jul. 2014.

WINTORY, Austin. Depoimento do compositor. Disponivel em: <http://designontherocks.blog.br/aarte-de-Journey/>. Acesso em 18 jul. 2014.

Vídeos:

Extra Credits - The Hero's Journey (part1). 2012. Disponivel em <http//www.youtube.com/ watch?v=SWKKRbw-eu4>. Acesso em 20 jul.2014

Extra Credits - The Hero's Journey (part1). 2012. Disponivel em <https://www.youtube.com/ watch?v=QVqT8s7bOTQ $>$. Acesso em 20 jul.2014 